\title{
Acute kidney injury with extreme hyperuricemia after antithymocyte globulin treatment in a kidney transplant recipient with underlying aplastic anemia: a case report
}

\author{
Yohan Park, Byung Ha Chung, Cheol Whee Park, Yong-Soo Kim and Chul Woo Yang* (1)
}

\begin{abstract}
Background: The occurrences of hyperuricemia and acute kidney injury after antithymocyte globulin treatment are unusual in kidney transplant recipients. Here, we report a unique case of acute kidney injury with extreme hyperuricemia after antithymocyte globulin treatment in a kidney transplant recipient with underlying aplastic anemia.

Case presentation: A 40-year-old woman with aplastic anemia who received a kidney transplant 5 years 6 months before presented to our emergency department with complaints of oliguria, generalized edema, and general weakness 6 days after receiving antithymocyte globulin treatment for acute T-cell-mediated rejection. Urinalysis revealed 100 uric acid crystal particles. The blood chemistry test results showed rapid increases in serum creatinine (from $2.86 \mathrm{mg} / \mathrm{dL}$ to $5.58 \mathrm{mg} / \mathrm{dL}$ ) and uric acid levels (from $10.2 \mathrm{mg} / \mathrm{dL}$ to $32.7 \mathrm{mg} / \mathrm{dL}$ ), which suggested acute uric acid nephropathy. Tumor lysis syndrome was suspected to be the cause of the acute uric acid nephropathy; hence, the patient was reevaluated for aplastic anemia. Human leukocyte antigen-DR15 was positive, and flow cytometry revealed a low percentage of glycophosphatidyl inositol-deficient granulocytes (2.9\%), which suggested paroxysmal nocturnal hemoglobinuria clones. These findings indicate that the previously diagnosed aplastic anemia had either originally been hypocellular myelodysplastic syndrome (MDS) or later transformed into hypocellular MDS, which is a type of bone marrow failure syndrome.
\end{abstract}

Conclusions: Clinicians should consider unexpected tumor lysis syndrome to be the cause of complications after antithymocyte globulin treatment in kidney transplant recipients with underlying bone marrow failure syndrome.

Keywords: Tumor lysis syndrome, Antithymocyte globulin, Aplastic anemia, Myelodysplastic syndrome, Kidney transplantation

\footnotetext{
* Correspondence: yangch@catholic.ac.kr

Division of Nephrology, Department of Internal Medicine, Seoul St. Mary's Hospital, College of Medicine, The Catholic University of Korea, 222

Banpo-daero, Seocho-gu, Seoul 06591, South Korea
}

(C) The Author(s). 2020 Open Access This article is licensed under a Creative Commons Attribution 4.0 International License, which permits use, sharing, adaptation, distribution and reproduction in any medium or format, as long as you give appropriate credit to the original author(s) and the source, provide a link to the Creative Commons licence, and indicate if changes were made. The images or other third party material in this article are included in the article's Creative Commons licence, unless indicated otherwise in a credit line to the material. If material is not included in the article's Creative Commons licence and your intended use is not permitted by statutory regulation or exceeds the permitted use, you will need to obtain permission directly from the copyright holder. To view a copy of this licence, visit http://creativecommons.org/licenses/by/4.0/. The Creative Commons Public Domain Dedication waiver (http://creativecommons.org/publicdomain/zero/1.0/) applies to the data made available in this article, unless otherwise stated in a credit line to the data. 


\section{Background}

Acute uric acid nephropathy is one of the causes of acute kidney injury (AKI). Acute uric acid nephropathy is most commonly caused by tumor lysis syndrome (TLS); however, it may also occur from rhabdomyolysis or other conditions $[1,2]$. When significant cell lysis occurs, large quantities of nucleotides are quickly released and metabolized in the liver, causing an increase in the serum uric acid level to $>12 \mathrm{mg} / \mathrm{dL}$. Increased renal excretion of uric acid causes supersaturation in the urine, while the formation of uric acid crystals leads to the obstruction of the tubule lumen [3, 4].

TLS is usually caused by treatment of hematologic malignancies with high turnover rates, such as acute myeloid leukemia (AML), acute lymphoid leukemia (ALL), or lymphoma [5], and is relatively rare in bone marrow failure syndromes, which shows the hypocellularity of the bone marrow [6, 7]. Moreover, TLS caused by antithymocyte globulin (ATG) administration has not been reported in kidney transplant $(\mathrm{KT})$ recipients to date. Here, we report a unique case of acute uric acid nephropathy presumably caused by ATG treatmentrelated TLS in a KT recipient with acute rejection who was previously diagnosed with aplastic anemia (AA).

\section{Case presentation}

A 40-year-old woman who underwent kidney transplantation 5 years 6 months before presented to our emergency department with complaints of oliguria, generalized edema, and general weakness 6 days after receiving ATG treatment for acute T-cell-mediated rejection.

She was diagnosed with severe AA 8 years before on the basis of a bone marrow biopsy that revealed $<5 \%$ cellularity without cytogenetic abnormalities and with an inadequate response to ATG. Thus, she was managed conservatively with intermittent red blood cell and platelet transfusions without cyclosporine owing to concomitant chronic kidney disease. End-stage renal disease developed 7 years before, for which the patient had been receiving peritoneal dialysis (PD) for 1 year. She was transferred to our hospital for simultaneous kidney and hematopoietic stem cell transplantation. At that time, we planned a sequential transplantation (kidney transplantation followed by hematopoietic stem cell transplantation) with her mother as the donor. The ABO blood type was compatible, and two mismatched human leukocyte antigen (HLA) types were found. Panel reactive antibodies were $75 \%$ positive for class II. The donor-specific antibody was DR04, and the median fluorescence intensity was 1865 . Rituximab $\left(375 \mathrm{mg} / \mathrm{m}^{2}\right)$ and basiliximab $(20 \mathrm{mg})$ were administered as induction therapies. Tacrolimus, mycophenolate mofetil (MMF), and glucocorticoids were used for maintenance immunosuppression. However, MMF was changed to mizoribine after the patient experienced severe diarrhea and dyspepsia 3 years 6 months after receiving the $\mathrm{KT}$.

After kidney transplantation, the AA improved gradually without a hematopoietic stem cell transplantation. The complete blood cell count $(\mathrm{CBC})$ improved with a hemoglobin $(\mathrm{Hb})$ level of $>9 \mathrm{~g} / \mathrm{dL}$ and platelet (PLT) count of $>50,000 / \mu \mathrm{L}$, indicating that blood transfusion was unnecessary. The bone marrow biopsy findings improved 16 months after the kidney transplantation (Fig. 1). Graft function was also well-maintained; however, the serum creatinine $(\mathrm{Cr})$ level increased gradually 5 years after kidney transplantation, reaching $2.41 \mathrm{mg} / \mathrm{dL}$ 5 years 5 months after transplantation. The graft biopsy revealed acute T-cell-mediated rejection type IA. We initially managed the patient with methylprednisolone pulse therapy (125 mg twice daily) for 5 days; however, her renal function deteriorated further after 1 month (Fig. 2). Thus, we administered ATG $1.5 \mathrm{mg} /(\mathrm{kg}$.day) for 5 days. At that time, we pre-medicated the patient with methylprednisolone for 5 days, with $500 \mathrm{mg}$ once and subsequently with $125 \mathrm{mg}$ twice daily for the following 4 days.

On the day of admission, the patient complained of general weakness and generalized edema and showed a pretibial pitting edema. Blood testing revealed high serum blood urea nitrogen and $\mathrm{Cr}$ levels with hyperuricemia, hyperphosphatemia, and hyperkalemia, consistent with TLS. Urinalysis revealed $>100$ uric acid crystal particles, and the uric acid-to- $\mathrm{Cr}$ ratio was 1.06 , which was consistent with acute uric acid nephropathy [8] (Table 1).

Two hemodialysis sessions were completed because of oliguria (urine output, <200 mL/day). After hemodialysis, the patient's serum uric acid and Cr levels remained at 3.3 and $3.96 \mathrm{mg} / \mathrm{dL}$, respectively, with a daily urine output of $>1500 \mathrm{~mL}$, and she was discharged (Fig. 2). TLS was suspected to be the cause of the acute uric acid nephropathy; therefore, post-transplantation lymphoproliferative disorder was considered a possibility. Epstein-Barr virus was not detected, and the imaging studies showed no findings indicative of lymphoma. Thus, the patient was reevaluated for the underlying hematologic disease. Flow cytometry of the paroxysmal nocturnal hemoglobinuria (PNH) clones revealed a $2.9 \%$ glycophosphatidyl inositol (GPI)-deficient granulocyte and a $2.9 \%$ CD24-deficient granulocyte expansion, which suggest that either the AA transformed into myelodysplastic syndrome (MDS) or the original underlying disease was MDS. Unfortunately, the patient progressed to graft failure 2 months after discharge and resumed PD.

\section{Discussion and conclusions}

The present case demonstrates the occurrence of an extremely high increase in serum uric acid level (>30 mg/ $\mathrm{dL}$ ) and AKI after ATG treatment in a KT recipient with 


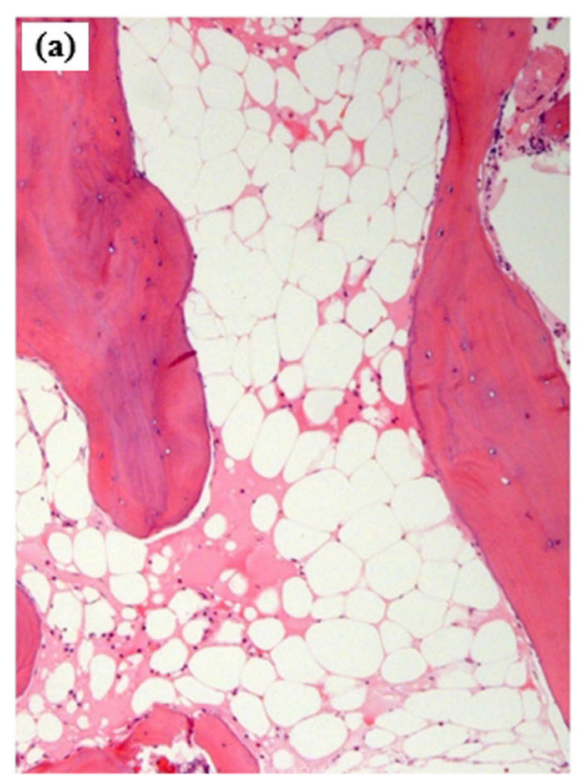

(c)
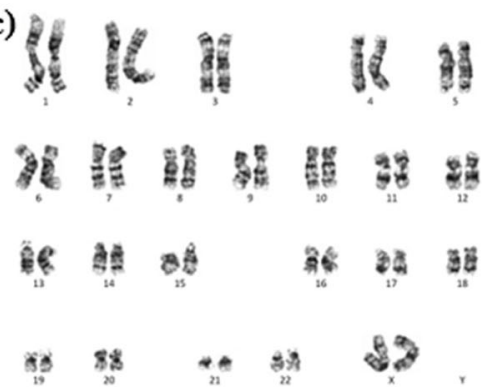

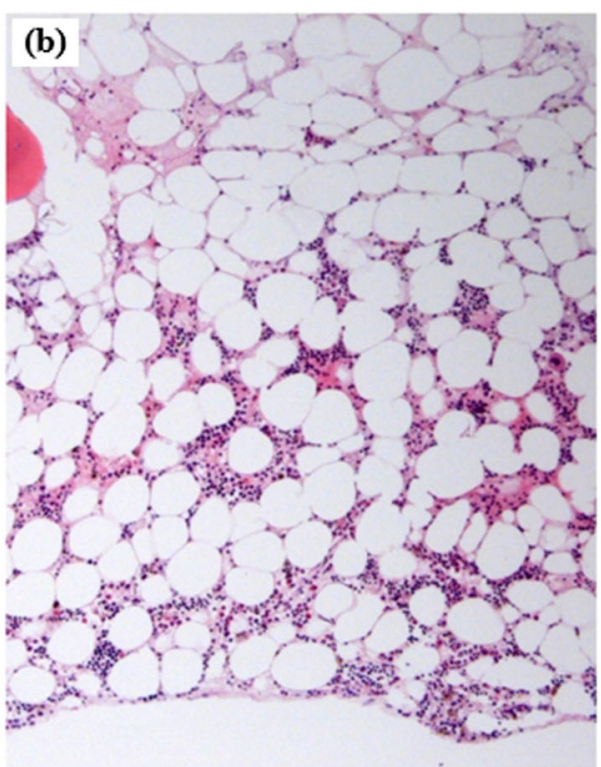

(d)

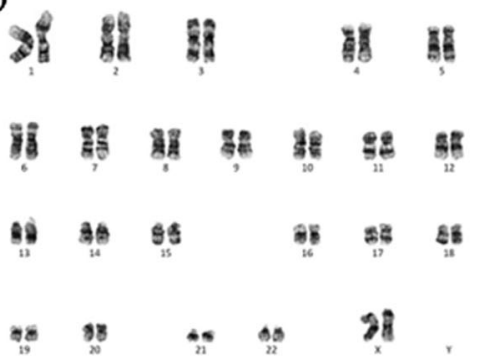

Fig. 1 Bone marrow biopsy findings before and after the kidney transplantation. a Bone marrow biopsy findings before and (b) 16 months after kidney transplantation. The bone marrow cellularity of < 5\% before the transplantation increased to $20 \%$ with normal hematopoietic differentiation. c Bone marrow biopsy karyotyping before and (d) 16 months after the kidney transplantation. Note the lack of cytogenetic abnormalities

underlying AA. We diagnosed the case as TLS based on the criteria for hyperuricemia, hyperphosphatemia, hyperkalemia, and AKI [9]. TLS usually presents within 7 days of cytotoxic chemotherapy [5] and most often occurs in hematologic malignancies with high turnover rates, such as AML and ALL, but is rarely reported in bone marrow failure syndromes such as AA and MDS $[7,9]$. This is the first report of acute uric acid nephropathy presumably caused by ATG treatment-related TLS in a KT recipient with a previous diagnosis of AA.

TLS development after ATG treatment is unusual. This case was characterized by a long, 8-year history of AA with gradual improvement after kidney transplantation. Thus, the underlying AA was considered the cause of the TLS. A case review revealed two interesting findings. First, the patient was HLA-DR15 positive. In previous studies, AA patients with HLA-DR15 positivity showed 8.53 times higher hematologic improvement with immunosuppressants and higher coexisting $\mathrm{PNH}$ and MDS rates than the negative group $[10,11]$. Second, the patient had PNH clones (2.9\% GPI- and 2.9\% CD24deficient granulocytes), which suggested subclinical $\mathrm{PNH}$. These features were consistent with those of a previous report that subclinical PNH in MDS patients showed a high HLA-DR15 positivity rate $(90.5 \%)$ and bone marrow hypocellularity (64.3\%). In addition, these patients often have normal karyotypic morphologies (95.2\%) and respond well to immunosuppressants (77.8\%) [12], as observed in the bone marrow biopsy findings from our case (Fig. 1). All the findings showed the possibility that the patient in this report either originally had hypocellular MDS or a previously diagnosed AA that had transformed into another type of bone marrow failure syndrome owing to clonal evolution [13, 14].

One may argue that high-dose methylprednisolone rather than ATG is responsible for the TLS in this case. Indeed, the development of TLS after high-dose methylprednisolone administration in MDS was previously reported [7]. In the review of our case, the patient was administered high-dose methylprednisolone two times 


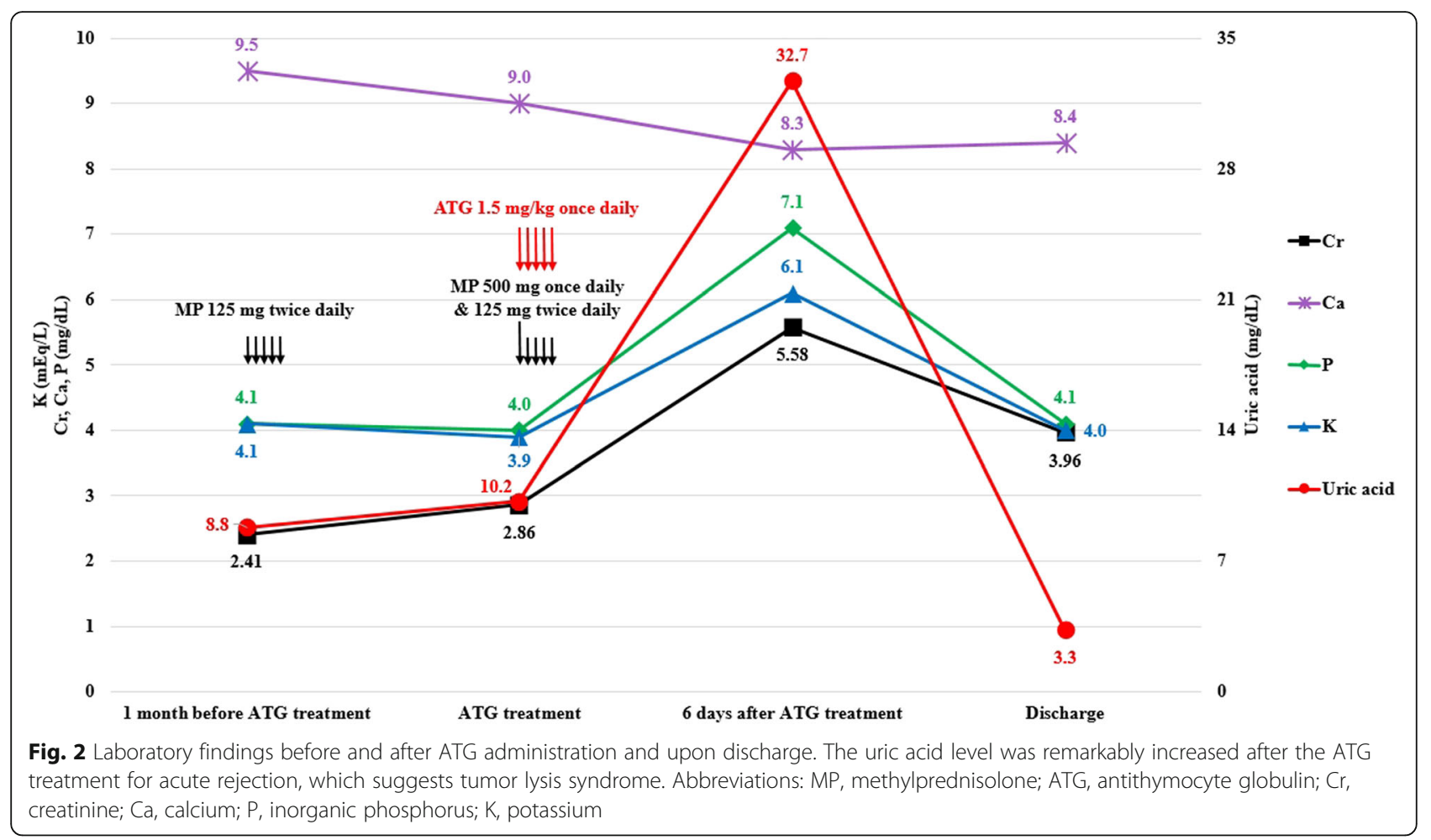

Table 1 Laboratory findings at the emergency department at 6 days after antithymocyte globulin administration

\begin{tabular}{|c|c|}
\hline \multicolumn{2}{|c|}{ The complete blood cell count and serum chemistry test findings } \\
\hline $\mathrm{WBC}\left(\times 10^{3} / \mathrm{\mu L}\right)$ & 13.4 \\
\hline $\mathrm{Hb}(\mathrm{g} / \mathrm{dL})$ & 7.6 \\
\hline $\operatorname{PLT}\left(\times 10^{3} / \mu \mathrm{L}\right)$ & 38 \\
\hline $\mathrm{BUN}(\mathrm{mg} / \mathrm{dL})$ & 73.1 \\
\hline $\mathrm{Cr}(\mathrm{mg} / \mathrm{dL})$ & 5.58 \\
\hline Uric acid (mg/dL) & 32.7 \\
\hline Calcium (mg/dL) & 8.3 \\
\hline Phosphorus (mg/dL) & 7.1 \\
\hline Potassium (mEq/L) & 6.1 \\
\hline Albumin (g/dL) & 2.6 \\
\hline $\mathrm{LDH}(\mathrm{U} / \mathrm{L})$ & 556 \\
\hline CPK $(U / L)$ & 8 \\
\hline \multicolumn{2}{|c|}{ The dipstick urinalysis and urine chemistry test findings } \\
\hline Hematuria & $1+$ \\
\hline Proteinuria & $1+$ \\
\hline Uric acid crystal (/HPF) & $>100$ \\
\hline Uric acid (mg/dL) & 46.4 \\
\hline $\mathrm{Cr}(\mathrm{mg} / \mathrm{dL})$ & 43.6 \\
\hline Uric acid / Cr ratio & 1.06 \\
\hline
\end{tabular}

Abbreviations: WBC, white blood cell; Hb Hemoglobin; PLT Platelet; BUN Blood urea nitrogen; $\mathrm{Cr}$ Creatinine; $L D H$ Lactate dehydrogenase; CPK Creatine phosphokinase; HPF High power field with a 1-month interval (acute rejection treatment and premedication for ATG). If the high-dose methylprednisolone administration was responsible for the TLS in our case, TLS should have occurred during the first administration of methylprednisolone for acute rejection treatment. Thus, we suggest ATG, rather than methylprednisolone, to be the cause of the TLS, and that the possible pathophysiology of the ATG therapy-related TLS in MDS is the presence of potentially chemosensitive hematologic malignant cells. This presumption may be supported by a previous report of rapid tumor cell lysis occurring after ATG therapy for Sezary syndrome (cutaneous T-cell lymphoma) [15].

In this case, mizoribine was used as a maintenance immunosuppressant. Previous studies reported that mizoribine might cause hyperuricemia in patients with renal dysfunction [16, 17]. Mizoribine use may have contributed to the extreme hyperuricemia in this case; however, despite continuing the mizoribine therapy after TLS event, hyperuricemia was not observed anymore. Thus, mizoribine was unlikely to be the main cause of acute uric acid nephropathy in this patient.

This report has some limitations. First, we could not confirm the hematologic disease because the patient was reluctant to undergo bone marrow biopsy after developing TLS. Therefore, whether the patient's underlying hematologic disease was MDS or AML was unclear. However, the patient's $C B C$ over the next 2 years after TLS event showed no evidence of blasts in peripheral 
blood that suggested AML. Second, whether the initial diagnosis of AA should have been hypocellular MDS is uncertain. However, our findings suggest that AA is a type of bone marrow failure syndrome that may overlap with other diseases or transform into another disease via clonal evolution during the disease course.

In conclusion, this was a unique case of ATG treatment-related TLS in a KT recipient previously diagnosed with AA. Thus, transplant clinicians should be cautious of the fact that the clinical course of AA may be more diverse than once thought and it can cause TLS in KT recipients receiving ATG treatment.

\section{Abbreviations}

AA: Aplastic anemia; AKI: Acute kidney injury; ALL: Acute lymphoid leukemia; AML: Acute myeloid leukemia; ATG: Antithymocyte globulin; CBC: Complete blood cell count; Cr: Creatinine; GPI: Glycophosphatidyl inositol; Hb: Hemoglobin; HLA: Human leukocyte antigen; KT: Kidney transplant; MDS: Myelodysplastic syndrome; MMF: mycophenolate mofetil; PD: Peritoneal dialysis; PLT: Platelet; PNH: Paroxysmal nocturnal hemoglobinuria; TLS: Tumor lysis syndrome

\section{Acknowledgements}

Not applicable.

\section{Authors' contributions}

BHC and CWY cared the patient; YP collected data and drafted the manuscript with CWY. CWP and YSK discussed the case together. All authors read and approved the final manuscript.

\section{Funding}

This research was supported by the Bio \& Medical Technology Development Program of the National Research Foundation (NRF) funded by the Ministry of Science \& ICT(2018M3A9E802151). This manuscript is a case report, researchers-led paper, with no specific participation by funders.

\section{Availability of data and materials}

Data sharing is not applicable to this article as no datasets were generated or analyzed during the current study.

\section{Ethics approval and consent to participate}

This case report was reviewed by the Institutional Review Board of Seoul St. Mary's Hospital and it was approved by an ethics committee (KC19ZESE0576).

\section{Consent for publication}

Written consent was obtained from the patient's mother for publication of the study because the patient died at the time of writing the manuscript.

\section{Competing interests}

The authors declare that they have no competing interests.

Received: 11 September 2019 Accepted: 22 June 2020

Published online: 02 July 2020

\section{References}

1. Ejaz AA, Mu W, Kang DH, Roncal C, Sautin YY, Henderson G, et al. Could uric acid have a role in acute renal failure? Clin J Am Soc Nephrol. 2007;2(1):1621.

2. Moreau D. Pharmacological treatment of acute renal failure in intensive care unit patients. Contrib Nephrol. 2005;147:161-73.

3. Kim YG, Huang XR, Suga S, Mazzali M, Tang D, Metz C, et al. Involvement of macrophage migration inhibitory factor (MIF) in experimental uric acid nephropathy. Mol Med. 2000;6(10):837-48.

4. Shimada M, Johnson RJ, May WS Jr, Lingegowda V, Sood P, Nakagawa T, et al. A novel role for uric acid in acute kidney injury associated with tumour lysis syndrome. Nephrol Dial Transplant. 2009;24(10):2960-4.
5. Howard SC, Jones DP, Pui CH. The tumor lysis syndrome. N Engl J Med. 2011;364(19):1844-54

6. Feng $Y$, Jiang $T$, Wang L. Hyperuricemia and acute kidney injury secondary to spontaneous tumor lysis syndrome in low risk myelodysplastic syndrome. BMC Nephrol. 2014;15:164

7. Yang SS, Chau T, Dai MS, Lin SH. Steroid-induced tumor lysis syndrome in a patient with preleukemia. Clin Nephrol. 2003;59(3):201-5.

8. Kelton J, Kelley WN, Holmes EW. A rapid method for the diagnosis of acute uric acid nephropathy. Arch Intern Med. 1978;138(4):612-5.

9. Cairo MS, Bishop M. Tumour lysis syndrome: new therapeutic strategies and classification. Br J Haematol. 2004;127(1):3-11.

10. Song EY, Kang HJ, Shin HY, Ahn HS, Kim I, Yoon SS, et al. Association of human leukocyte antigen class II alleles with response to immunosuppressive therapy in Korean aplastic anemia patients. Hum Immunol. 2010:71(1):88-92.

11. Saunthararajah Y, Nakamura R, Nam JM, Robyn J, Loberiza F, Maciejewski JP, et al. HLA-DR15 (DR2) is overrepresented in myelodysplastic syndrome and aplastic anemia and predicts a response to immunosuppression in myelodysplastic syndrome. Blood. 2002;100(5):1570-4.

12. Wang H, Chuhjo T, Yasue S, Omine M, Nakao S. Clinical significance of a minor population of paroxysmal nocturnal hemoglobinuria-type cells in bone marrow failure syndrome. Blood. 2002;100(12):3897-902.

13. Maciejewski JP, Balasubramanian SK. Clinical implications of somatic mutations in aplastic anemia and myelodysplastic syndrome in genomic age. Hematology Am Soc Hematol Educ Program. 2017;2017(1):66-72.

14. Afable MG 2nd, Tiu RV, Maciejewski JP. Clonal evolution in aplastic anemia. Hematology Am Soc Hematol Educ Program. 2011;2011:90-5.

15. Fisher RI, Kubota TT, Mandell GL, Broder S, Young RC. Regression of a T-cell lymphoma after administration of antithymocyte globulin. Ann Intern Med. 1978;88(6):799-800.

16. Shi Y, Liu H, Chen XG, Shen ZY. Hyperuricemia in living donor kidney transplantation patients during Mizoribine administration caused mainly by changes in kidney function. Transplant Proc. 2019:51(5):1392-6.

17. Chen $P, X u X, L i u L, W u J, L i J$, Fu Q, et al. Prediction of mizoribine pharmacokinetic parameters by serum creatinine in renal transplant recipients. Eur J Clin Pharmacol. 2019;75(3):363-9.

\section{Publisher's Note}

Springer Nature remains neutral with regard to jurisdictional claims in published maps and institutional affiliations.

\section{Ready to submit your research? Choose BMC and benefit from:}

- fast, convenient online submission

- thorough peer review by experienced researchers in your field

- rapid publication on acceptance

- support for research data, including large and complex data types

- gold Open Access which fosters wider collaboration and increased citations

- maximum visibility for your research: over $100 \mathrm{M}$ website views per year

At BMC, research is always in progress.

Learn more biomedcentral.com/submission 